\title{
New Members of the European Physical Society
}

\section{CATEGORY 4a)}

M.L. Browne, Garching, D

P.A. Burla, Grand-Saconnex, $\mathrm{CH}$

J.M. Lagniel, Gif-sur-Yvette, F

H.D. Lustig, Geneva, CH

P. Mandrillon, Nice, F

W. Schnell, Geneva, $\mathrm{CH}$

J.R. Huber, Zürich, $\mathrm{CH}$

F. Schreier, Planegg, A

H.F. Weehuizen, Faure, South Africa

\section{CATEGORY 4c)}

Austrian Physical Society

B. Ortner, Leoben

Belgian Physical Society

J. Broeckhove, Wilriik

P. Dendooven, Heverlee

A. Dereux, Namur

A.-M. Empsten, Edegem

M. Piette, Namur

Danish Physical Society

H.E. Hjelmroth

Department of General Physics and

Astronomy of the USSR Academy of Sciences

A.A. Abrikosov, Moscow

Y. Gulyaev, Moscow

French Physical Society

H. Benoit, Strasbourg

Ch. Blondel, Cachan

Y. Brechet, Grenoble

B. Cagnac, Paris

P. Daniel, Le Mans

P. Friedel, Eindhoven, NL

A. Friedrich, Paris

G. Gasser, Metz

E. Kajfasz, Marseille

M. Lanno, Mouvaux

C. Lhuillier, Paris

P. Manneville, Gif-sur-Yvette

M. Mordant, Villennes-sur-Seine

R. Mosseri, Meudon

M. Olivier, Gif-sur-Yvette

S. Roux, Paris
Eötvös Lorand Physical Society

T. Major, Budapest

M. Menyhard, Budapest

German Physical Society

E. Andrejew, Wiesbaden

A. Berger, Aachen

W. de Boer, Hamburg

R. Dennert, München

D. Durek, Hachenburg

$H$. Ehrentraut, Berlin

G.C. Fox, Hamburg

L.R. Frost, Bielefeld

D. Glatzer, Stuttgart

D. Haarer, Bayreuth

W. Harbich, Bussigny, $\mathrm{CH}$

W. Herr, Geneva, $\mathrm{CH}$

J.V. Hofmann, Garching

$U$. Knorr, Düsseldorf

M. Köllner, Heidelberg

R.R. Landes, Bonn

T. Krallmann, Bonn

T. Müller, Crozet, $F$

P.F. Oltmann, Jülich

G. Plass, CERN, Geneva, CH

F.J. Ruff, Stuttgart

P.M. Schmidt, Paris, F

R. Schmidt, Berlin

M.M. Sieck, Karisruhe

H. Waldmann, Berlin

R. Wessel, Cambridge, GB

\section{Hellenic Physical Society}

C. Skordoulis, Ioannina

The Institute of Physics

$M$. Bhatt, London

T.P. Donaldson, Chelmsford

G.A. Gehring, Sheffield

J.D. Gray, Glasgow

W.G. Griffin, Reading

A.D. Irving, Abingdon

T.P. Lamuren, Sagamu, Nigeria

S. Messoloras, Athens, GR

J.K. O'Neill, Southsea

A.P. Pathak, Hyderabad, India

T.A. Roberts, Congleton

D.R. Wilkinson, Guildford
Italian Physical Society

L.C. Andreani, Lausanne, $\mathrm{CH}$

L. Belloni, Milano

M. Placidi, Geneva, $\mathrm{CH}$

G.F. Tantardini, Milano

P. Tucci, Milano

The Netherlands' Physical Society

P.F.A. Alkemade, London, Canada

F.A. Berends, Leiden

$\mathrm{H}$. Chang, Amstelveen

J.B. Goedkoop, Alkmaar

R.P. Griessen, Amsterdam

W. Hoogland, Ferney-Voltaire, F

J. Kunnen, Noordwijkerhout

G. Ooms, Aerdenhout

J. Schmidt, Leiden

I. Ten Have, Geneva, $\mathrm{CH}$

G.E. van Dorssen, Nieuwegein

Norwegian Physical Society

B. Stölan, Trondheim

Physical Section, Union of Czechoslovak Mathematicians and Physicists

O. Hudak, Kosice

P. Lichard, Bratislava

F. Smutny, Prague

M. Solc, Prague

P. Valko, Bratislava

T. Zeithamer, Kunratice

Physical Section, Union of Yugoslav Societies of Mathematicians,

Physicists and Astronomers

D. Zavratanik, Geneva, $\mathrm{CH}$

Polish Physical Society

K. Polanski, Lodz

Romanian National Committee for Physics

A.C. Gheorghe, Bucharest

V. Gheorghe, Bucharest

A. Oncica, Bucharest

V. Topor Pop, Magurele
Physical Society of the German

Democratic Republic

V. Brückner, Jena

D. Demus, Halle

D. Ebert, Berlin

B. Fleck, Jena

A. Förstner, Berlin

M. Hartmann, Berlin

D. Hoffmann, Berlin

C. Illgen, Berlin

M. Marz, Berlin

G. Notni, Potsdam

1. Rotter, Dresden

G. Röpke, Rostock

A. Schaale, Berlin

W. Ulrici, Berlin

R. Zimmermann, Berlin

Spanish Royal Society of Physics

R.M. Benito, Madrid

J.M. Lopez Sancho, Madrid

J.M. Massaguer, Barcelona

L. Navarro, Barcelona

A. Poves, Madrid

J.A. Rubio, Geneva, $\mathrm{CH}$

Swiss Physical Society

W. Joho, Villigen

Turkish Physical Society

$M$. Gündüz, Kayserie

\section{CATEGORY 4d)}

American Physical Society

C. Alejaldre, Madrid, E

G. Croon, Eltville-am-Rhein, D

J.P. Dowling, Garching, D

E. Fazio, Rome, 1

W. Hudry, Ft. Meade, MD

C. Manolis, Evia, GR

A. Perez-Navarro, Madrid, E

French Optical Society

M. Schneider, Nice

Société Française des Spécialistes en Astronomie

B.H. Foing, Noordwijk, NL

\section{Mathematical Sciences in Cambridge}

The Science and Engineering Research Council in the UK has recently agreed to contribute f2 $\mathrm{M}$ over 6 years to match offers of contributions from various sources in Cambridge to set up the Isaac Newton Institute for Mathematical Sciences, a new national institute for research in the mathematical sciences, including theoretical physics. St. John's College had already offered to construct a purpose-built building on part of a seven acre residential site in Cambridge and make it available rent-free for five years. Meanwhile, Trinity College and the University have offered to grant $f 1.1 \mathrm{M}$, but their offers are conditional on there being additional funding of $f 400 k$ per year for five years.

The coordinator of the project, Pr. Peter Landshoff is presently determining whether or not the Cambridge sources agree that the SERC funding is adequate to allow building of the new Institute to start. There is some urgency because it is hoped to launch the first programme in 1992, which means that invitations to visiting researchers must be sent out within a few months.
The Institute, although modelled on the highly successful Institute for Theoretical Physics at the University of California, Santa Barbara, aims to cover a much wider field involving all branches of mathematical sciences. In recent years there have been exciting developments in many of these branches, with new and deep connections emerging between subjects which previously appeared unrelated. It will obviously be necessary to define a fairly limited programme at the onset so it is planned to invite leading scientists to join a selection committee in October 1990.

The Institute aims to keep the UK at the forefront of research in the mathematical sciences by stimulating research through the organisation of visitor programmes bringing together UK and international experts. Individual programmes will typically last for six months and involve about 20 mathematical scientists meeting together for research on specialised topics through lectures, seminars and informal contacts. It is planned to have four programmes each year that will bridge expertise in several areas to encourage cross-fertilisation.

Each visitor programme will usually be run by two or three experts from outside Cambridge (often from overseas). The programmes will be, in principle, open to anyone with a Ph.D. but generally speaking they will be tailored for advanced postdocs with a few years' research behind them.

The organisers are aware that it will be important to make it as easy as possible for researchers from other universities and institutes to participate fully by providing office space, travel funds, board and lodging. Lecturers' salaries must also be paid. The most difficult task is to find funds to pay the salaries of selected visitors who would otherwise be unable to participate.

Cambridge offers an undeniably attractive site for the new Institute, and the University can provide a supportive environment for the Institute's interdisciplinary activites. Further information can be obtained from Dr. Peter Landshoff, DAMPT, University of Cambridge, Silver Street, Cambridge, CB3 9EW, UK (bitnet: prl @ ukacrl). Tel: ++41-223-337880; fax: ++ 41-223-337918. 